\title{
Accuracy of routine intraocular lens power calculation in a district general hospital
}

\author{
P T S GREGORY, R M ESBESTER, AND D L BOASE \\ From Queen Alexandra Hospital, Cosham, Portsmouth
}

SUMMARY To assess the accuracy of routine preoperative biometry we reviewed all cases of extracapsular cataract extraction with posterior chamber implant performed at Queen Alexandra Hospital in 1985 . Of 471 eyes included in the survey $67.9 \%$ were within $1.0 \mathrm{D}$ of the expected refraction and $90.7 \%$ within $2.0 \mathrm{D}$. Factors influencing accuracy are discussed. The necessity of routine preoperative biometry is emphasised.

There is increasing evidence of the value of preoperative biometry to calculate the power of an intraocular implant used during cataract surgery to avoid the large range of postoperative refractive error associated with the use of a standard-power lens. This led to the adoption of biometry in our hospital during 1984 and its routine use throughout 1985 . The purpose of this study was to measure the accuracy of our biometry and discover reasons for any errors in the hope that these might be minimised in the future.

\section{Materials and methods}

All cases of extracapsular cataract extraction with implantation of a posterior chamber intraocular lens (IOL) performed at Queen Alexandra Hospital in 1985 were reviewed, except where penetrating keratoplasty was simultaneously performed. From this total of 528 cases 57 cases were excluded for various reasons (Table 1), leaving 471 eyes in the survey.

A Haag-Streit Javal-Schiøtz keratometer was used for keratometry in every case. Axial length was measured with a Coopervision Ultrascan $2,10 \mathrm{MHz}$, liquid probe until September 1985, when a 3-M Digiecho, $10 \mathrm{MHz}$, solid probe was used mounted on a double table with the keratometer. This arrangement made biometry much more rapid and convenient. We used IOLAB Sinskey style lenses with $10^{\circ}$ forward angled loops, many with laseridge and ultraviolet filter (Model nos. G707G and G757G).

Correspondence to PTS Gregory, FRCS, Department of Ophthalmology, Charing Cross Hospital, Fulham Palace Road, London W6 8RF.
Biometry was carried out by optometrists, consultants, and junior doctors. Twelve people with varying degrees of experience made the measurements.

For each patient the following steps were taken. First, keratometry and axial length measurement of each eye were performed and spectacle prescription recorded. A decision was then made on the desired postoperative refraction. Generally we aimed for emmetropia or slight myopia, but in an ametrope with vision of $6 / 24$ or better in the other eye we aimed for two dioptres less ametropia than in the other eye to avoid possible problems from aniseikonia and anisometropia.

Next the power of intraocular lens for emmetropia was calculated from the Sanders, Retzlaff, and Kraff (SRK) formula ${ }^{1}$ :

$\begin{gathered}\text { IOL power } \\ \text { (dioptres) }\end{gathered}=A-2.5 \quad \underset{(\mathrm{mm})}{(\text { axial length) }}-0.9 \begin{gathered}\text { (mean keratometry) } \\ \text { (dioptres) }\end{gathered}$

The A constant recommended for this lens is $116 \cdot 8$, but may be modified by any surgeon in the light of his experience.

Where ametropia was desired, this calculation was adjusted by the formula:

Power $_{\mathrm{am}}=$ Power $_{\mathrm{emm}} \pm 2 / 3$ (dioptres ametropia required). (The effectivity of a lens at the implant plane is $2 / 3$ that of a lens at the spectacle plane.)

For example, if the SRK formula suggested a 21dioptre lens for emmetropia in a given case, then if 2 dioptres myopia were desired postoperatively a 24dioptre lens would be required.

We now decided on the power of implant to use, bearing in mind the desired postoperative refraction and also that lenses were available only in half- 
Table 1 Patients excluded from survey

1. Biometry not performed:

(a) No reason given: 14 cases

(b) Reasons given: 10 cases: 6 difficult eyes 4 difficult patients

2. Post-op. refraction data unavailable:

(a) 9 Cases where refraction was not accurately recorded because acuity was too low to confirm retinoscopy subjectively:

2 central retinal vein occlusions

2 disciform macular degenerations

1 ischaemic optic neuropathy

1 retinal detachment

1 cystoid macular oedema

1 open-angle glaucoma

1 implant subluxation

(b) 6 Cases died before refraction.

(c) 5 Cases were refracted elsewhere.

(d) 3 Cases moved away before refraction.

(e) 3 Cases acuity 'too good' for refraction.

(f) 1 Case did not attend for follow-up.

3. Records missing despite repeated searches:

4. Biometry data illegible:

Total exclusions
5 cases

1 case

57 cases dioptre steps. We calculated the exact postoperative refraction expected from this approximately correct intraocular lens. For example: Suppose biometry indicates that a 20.85 D implant will give emmetropia. A $21.0 \mathrm{D}$ implant is used. Postoperatively this eye should have a refraction of: $2 / 3(20 \cdot 85-21 \cdot 0)=$ $-0 \cdot 10 \mathrm{D}$. This is the expected refraction with which the actual postoperative refraction is compared to assess the acuracy of our biometry.

Six to eight weeks after operation the eye was refracted and astigmatism with the rule was corrected by cutting and removing some or all of the interrupted 10-0 nylon sutures ${ }^{2}$ (see below).

The final refraction was performed within 12 weeks, and the difference between this and the expected refraction was recorded in each case. These figures quantify the accuracy of our biometry. As a comparison, an estimate was also made (by means of the two-thirds effectivity factor) of the expected postoperative refraction if a $21 \cdot 0$-dioptre lens had been used in each case.

\section{Results}

The accuracy of our biometry was determined by recording the dioptric value of: (actual refraction)(expected refraction) in each case.

Over all cases the mean of this difference was $-0 \cdot 17$ dioptre, indicating that on average the eyes ended up 0.17 dioptre more myopic than expected. The standard deviation of this difference was 1.71 dioptres.

The equivalent figures estimated if a 21.0 D lens had been used in each case were: mean postoperative refraction $-1.08 \mathrm{D}$, with standard deviation $2.68 \mathrm{D}$. An average of emmetropia for our patients would therefore have been achieved if the standard lens power had been $19 \cdot 38 \mathrm{D}(21+3 / 2(-1 \cdot 08)=19 \cdot 38)$. The large standard deviation would of course not be affected.

The only caution in comparing these figures is that our accuracy is not totally transferred to the patient owing to the half-dioptre steps between available implants. From this a patient can expect on average $0.083 \mathrm{D}$ less accuracy than if an infinite range of powers were available. This is evidently of no practical consequence.

The percentage of cases falling in given dioptre

Table 2 Percentage of cases within dioptre ranges

\section{Biometry}

$90.66 \%$ of cases were within $\pm 2.0 \mathrm{D}$ of the expected refraction. $84.29 \%$ of cases were within $\pm 1.5 \mathrm{D}$ of the expected refraction. $67.94 \%$ of cases were within $\pm 1.0 \mathrm{D}$ of the expected refraction. $40.76 \%$ of cases were within $\pm 0.5 \mathrm{D}$ of the expected refraction. Standard $21.0 \mathrm{D}$ lens

$70.02 \%$ of cases were within $\pm 2.0 \mathrm{D}$ of emmetropia. $56.96 \%$ of cases were within $\pm 1.5 \mathrm{D}$ of emmetropia.

$42.83 \%$ of cases were within $\pm 1 \cdot 0 \mathrm{D}$ of emmetropia. $20.56 \%$ of cases were within $\pm 0.5 \mathrm{D}$ of emmetropia.

Fig. 1 Numbers of patients in $0 \cdot 2$ dioptre steps.

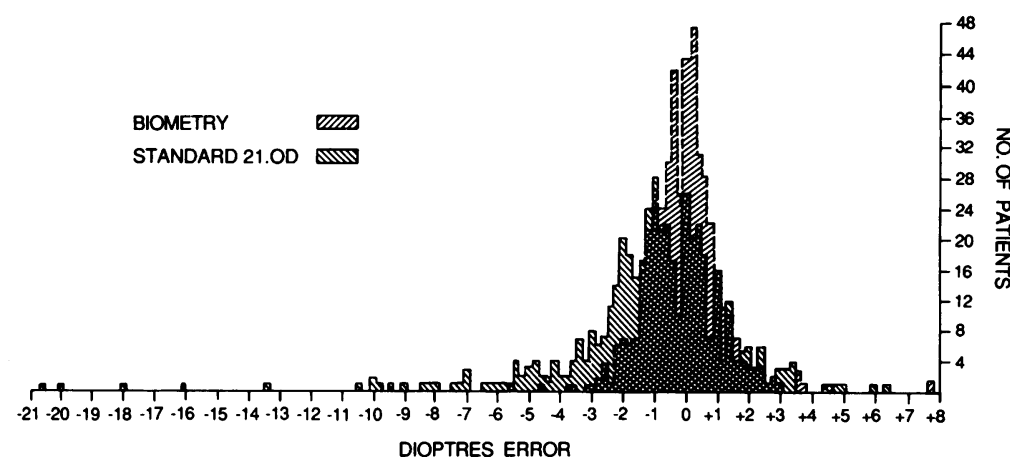


ranges from biometry and the standard $21.0 \mathrm{D}$ lens is shown in Table 2 , and a histogram of numbers of eyes in $\mathbf{0} \cdot 2$ dioptre steps is shown in Fig. 1.

As mentioned above, in some cases sutures were cut to reduce astigmatism. This was generally done when there was a positive cylinder of 2 or more dioptres with a near vertical axis $\left(60^{\circ}-120^{\circ}\right.$ approximately). In all, 384 sutures were removed from 100 eyes, with a mean reduction of 1.21 dioptres cylinder per suture. Overall mean sphere refraction of an eye was not affected by suture removal.

\section{Discussion}

Other surveys ${ }^{13-17}$ have studied the value of preoperative biometry for calculating the power of intraocular lenses for the correction of aphakia. This survey is unusual in examining a large number of cases and representing a whole year's workload from a district general hospital. Our figures compare favourably with other published studies. ${ }^{47_{10-1318}}$ We were anxious to include all possible cases regardless of biometric difficulty. A subjective confirmation of refraction was obtained in most cases, but in some cases retinoscopy was considered sufficiently accurate.

Our figures of $90.66 \%$ of cases within \pm 2.0 dioptres of expected refraction show that encouraging accuracy is being achieved. In some centres biometry is not undertaken and a standard power lens is used (usually 21.0 D for the type of posterior chamber lens we are using). Our figures show that this method would have produced a much wider range of postoperative refraction than did biometry.

Other centres vary the implant power according to the pre-cataract spectacle refraction. The usual formula used is:

$$
\mathrm{IOL} \text { power }=21+3 / 2 \text { (pre-cataract spectacle refraction). }
$$

It is well established that the dioptric power of an eye depends on corneal curvature, crystalline lens position and power, ${ }^{319}$ and axial length. In any group of emmetropic eyes there will be found a wide range of these four variables, despite their identical overall refraction. This is why spectacle refraction alone gives such a poor guide to implant power, as has been shown by other studies. ${ }^{3-5810}$ There is also little correlation between fellow eyes of axial length, keratometry, and anterior chamber depth. ${ }^{19}$

We re-examined the records of our worst resultsthat is, the 44 eyes where the final refraction differed from expected by 2.0 dioptres or more. The errors ranged from -20.0 dioptres (subsequently remeasured and found to have been grossly mismeasured preoperatively) to +8.75 dioptres. We listed the apparent main causes of error (see Table 3 ).
Table 3 Reasons for inaccuracy

\begin{tabular}{lcr}
\hline & $N o$. & $\%$ \\
\hline No obvious reason & 16 & $36 \cdot 4$ \\
Biometric difficulties & 15 & $34 \cdot 0$ \\
Long eyes & 13 & $29 \cdot 5$ \\
Short eyes & 1 & $2 \cdot 3$ \\
Proved mismeasurement & 5 & $11 \cdot 4$ \\
Surgical problems & 3 & $6 \cdot 8$ \\
Records unavailable & 1 & $2 \cdot 3$ \\
\hline
\end{tabular}

In some cases two or more of these factors were present.

Biometric difficulties were ascribed to a number of factors: (a) Mental and physical problems made measurements technically difficult. (b) Ocular problems were: dense cataracts causing poor transmission of ultrasound; cataracts and macular disease causing poor fixation; corneal irregularities causing poor keratometry. (c) Many of these cases were measured by inexperienced biometricians.

Several cases showing the more extreme errors were remeasured and found to have been wrongly measured before surgery. We found only one short $(<21 \mathrm{~mm})$ eye in the inaccurate group, but 10 long eyes $(>25 \mathrm{~mm})$. This is $22.7 \%$ of our worst cases in comparison with $7 \%$ of the whole survey. Some authors advocate the use of a different formula to calculate implant power in long and short eyes. 11420

Surgical problems may have contributed to the inaccuracy of the results of biometry in three of these cases. In one case the implant was nasally displaced, potentially affecting the refraction; one wound had to be resutured; and one posterior capsule was ruptured.

Another possible source of error is the degree of accuracy of the stated implant power, which has been questioned, but which recent studies have shown to be of a very high standard. ${ }^{2122}$ We have therefore relied on the quality control figures of the manufacturers.

Our results show that preoperative biometry is a practicable routine procedure in a district general hospital and has proved very useful in the accurate correction of aphakia with intraocular lens implantation. Our results compare well with those in other published series despite the fact that measurements were undertaken by no fewer than 12 people and all difficult cases have been included wherever possible. We consider that biometry should be part of the routine preoperative examination in all cases where intraocular lens implantation is being considered.

We thank the Consultants at Queen Alexandra Hospital for permission to report on their patients, and Lieut. Commander J R Wills, RN, for help with data analysis. 


\section{References}

1 Sanders DR, Kraff MC. Improvement of intraocular lens power calculation using empirical data. Am Intraocular Implant Soc J 1980; 6: 263-7.

2 Roper-Hall MJ. The control of astigmatism after surgery and trauma. Br J Ophthalmol 1982; 66: 556-9.

3 Binkhorst RD. Pitfalls in the determination of intraocular lens power without ultrasound. Ophthalmic Surg 1976; 7: 69-82.

4 Summers CG, Lindstrom RL. Secondary IOL power calculations: a comparison of regression formula and refraction method in accurate prediction of emmetropia. Am Intraocular Implant Soc J 1984; 10: 448-50.

5 Kraff MC, Sanders DR, Lieberman HL. Determination of intraocular lens power: a comparison with and without ultrasound. Ophthalmic Surg 1978; 9: 81-4.

6 Maloney WF, Kratz RP, Mazzocco TR, Davidson B. Posterior chamber intraocular lens power calculation in 441 cases. $\mathrm{Am}$ Intraocular Implant Soc J 1979; 5: 349-50.

7 Retzlaff J. Posterior chamber implant power calculation: regression formulas. Am Intraocular Implant Soc J 1980; 6: 268-70.

8 Hillman JS. The computer calculation of intraocular lens power. A clinical study. Trans Ophthalmol Soc UK 1980; 100: 222-8.

9 Hoffer KJ. Accuracy of ultrasound intraocular lens calculation. Arch Ophthalmol 1981; 99: 1819-23.

10 Hillman JS. The selection of intraocular lens power by calculation and by reference to refraction: a clinical study. Trans Ophthalmol Soc UK 1982; 102: 495-7.

11 Shammas HJF. The fudged formula for intraocular lens power calculations. Am Intraocular Implant Soc J 1982; 8: 350-2.
12 Hillman JS. Intraocular lens power calculation for planned ametropia: a clinical study. $\mathrm{Br}$ J Ophthalmol 1983; 67: 255-8.

13 Percival P. Lens power calculation: is it necessary? Trans Ophthalmol Soc UK 1983; 103: 577-9.

14 Thompson JT, Maumenee AE, Baker CC. A new posterior chamber intraocular lens formula for axial myopes. Ophthalmology 1984; 91 : 484-8.

15 Tutton MK. Intraocular lens power calculation using the SRK formula: a clinical study. Trans Ophthalmol Soc UK 1985; 104: 675-80.

16 Thompson SM, Mohan-Roberts V. A comparison of postoperative refractive results with and without intraocular lens power calculation. Br J Ophthalmol 1986; 70: 22-5.

17 Mathers WD, Grutzmacher RD. Lens implant calculations using an average of several formulas. Contact Lens Association of Ophthalmologists J 1986; 12: 216-8.

18 Johns GE. Clinical evaluation of the DBR A-scan unit. $A m$ Intraocular Implant Soc J 1979; 5: 213-6.

19 Hoffer KJ. Biometry of 7500 cataractous eyes. Am J Ophthalmol 1980; 90: $360-8$.

20 Shammas HJ. A comparison of immersion and contact techniques for axial length measurement. Am Intraocular Implant Soc J 1984; 10: 444-7.

21 Olson RJ. Intraocular lens optical quality: update 1979. Am Intraocular Implant Soc J 1980; 6: 16-7.

22 Olson RJ, Kolodner H, Kaufman HE. The optical quality of currently manufactured intraocular lenses. Am J Ophthalmol 1979; 88: 548.

Accepted for publication 26 November 1987. 